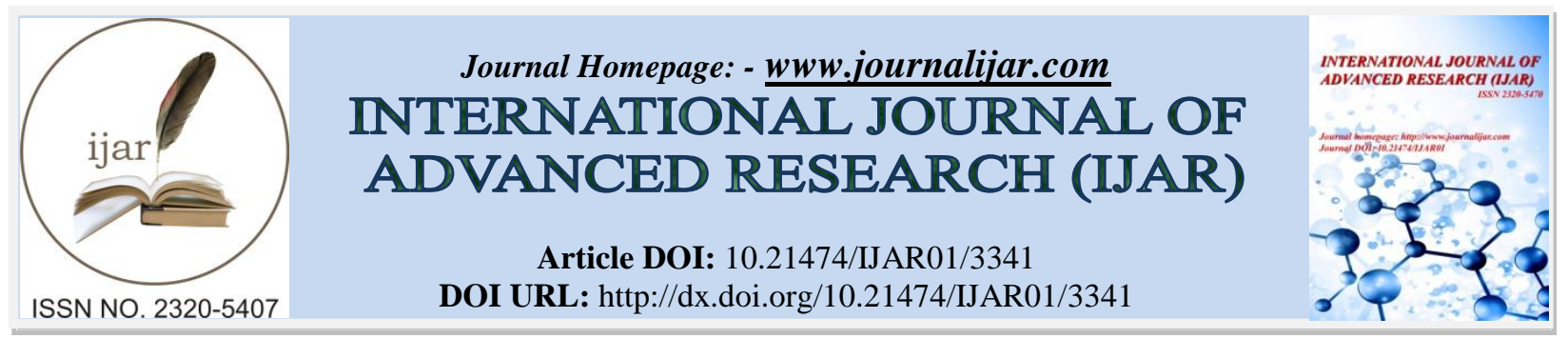

RESEARCH ARTICLE

\title{
FEBRILE CONVULSIONS AND IRON DEFICIENCY ANEMIA: A CASE-CONTROL STUDY IN ZAGAZIG UNIVERSITY HOSPITALS, EGYPT.
}

\section{Walid M. Reda Ashour, Hala A. Fathy, Tamer S. Elserafy and Wael Mahmoud.}

Department of Neurology, Faculty of Medicine, Zagazig University.

\section{Manuscript Info}

Manuscript History

Received: 20 December 2016

Final Accepted: 26 January 2017

Published: February 2017

Key words:-

Febrile convulsion, iron deficiency anemia, children.

\section{Abstract}

Background: Febrile convulsion (FC) is the most common convulsive disorder in children. The maximum age of occurrence is 14-18 months, which overlaps with the maximum prevalence of iron deficiency anemia (IDA) which is 1-2 years old.

Aim: To compare the iron deficiency rates in children with febrile convulsions with those in the febrile children without convulsions.

Subjects: This case-control study included 50 FC children (case group) with mean age of $30.3 \pm 19.2$ months and 50 children with febrile illness without convulsion (control group) with mean age of $28.8 \pm 19.3$ months attended to outpatient clinics of Neurology and Pediatric Departments, Zagazig University hospitals.

Methods: All patients had detailed history taking, thorough clinical general and neurological examination, laboratory tests (complete blood count, hemoglobin level, hematocrit value, mean corpuscular volume, serum ferritin level, serum iron level, total iron-binding capacity), and EEG .

Results: Respiratory tract infection \& history of previous seizure were significantly higher in cases. Microcytosis \& IDA were significantly more frequent in febrile seizure group. Median serum iron \& mean serum ferritin levels were significantly lower in cases. Generalized seizures were significantly higher and the mean duration of seizures was significantly longer in cases with iron deficiency than in those without iron deficiency. Focal seizures were significantly more frequent in cases without iron deficiency.

Conclusion: children with low serum iron level and those having iron deficiency anemia are more liable to develop FC when compared with those with febrile illness without convulsion.

Copy Right, IJAR, 2017,. All rights reserved.

\section{Introduction:-}

The most common neurologic problem in children is convulsion which occurs in 4-10\% of children before the age of 16 [1]. Febrile Convulsion (FC) refer to the convulsion that happens in children between the ages of six months and five years, with body temperature of $38^{\circ} \mathrm{C}$ or higher, not resulting from central nervous system infection or any metabolic imbalance and without any preceding afebrile seizures [2].

Febrile convulsion is the most common convulsive disorder in children, which affects $2-5 \%$ of neurologically healthy children aged 6 to 60 months [3]. 
The most frequent micronutrient deficiency is iron deficiency (ID) which influences at least one third of the planet's population. Anemia is the most frequent clinical manifestation of iron deficiency, nevertheless, other systems and organs may also be affected. Restless leg syndrome, disturbance in behavior, Cognitive dysfunction, psychomotor retardation, pica, breath holding attacks and thrombosis have been linked to iron deficiency [4].

The age of FC maximum occurrence is 14-18 months, which overlaps with the age of maximum prevalence of iron deficiency anemia (IDA) which is 12-24 months [5].

Conflicting results have been shown by researchers about the association between iron deficiency and seizures [1]. Reports from some studies declared that the incidence of febrile convulsion in patients with IDA is higher significantly than that in control group [6,7]. Per contra, other studies concluded that the risk of FC in children without IDA appears to be more than that in children with IDA [8]. At last, other studies found no role of IDA in pediatric FC $[\mathbf{9 , 1 0 ]}$.

\section{Aim of Work:-}

This study was done to compare the rates of both iron deficiency and iron deficiency anemia in children with febrile convulsions with those in febrile children without convulsions.

\section{Subjects:-}

This is a cross sectional case-control study that enrolled 50 children who presented with febrile convulsion (27 males and 23 females with mean age of 30.3 \pm 19.2 months) as case group and 50 sex and age-matching children who presented with non-neurological febrile illness without convulsion (26 males and 24 females with mean age of $28.8 \pm 19.3$ months) as control group from June 2015 to June 2016 presented to outpatient clinics of Neurology and Pediatric Departments, Zagazig University Hospitals.

- Informed consents were taken from the patients' parents.

\section{Methods:-}

A-Inclusion criteria:

1. Case group: included only patients presenting with their first febrile convulsion (febrile convulsion defined as the convulsion that occur in children between the ages of six months and five years, with body temperature of $38^{\circ} \mathrm{C}$ or higher not resulting from central nervous system infection or any metabolic imbalance without any prior afebrile seizures [2].

2. Control group: included only age and sex matched patients who presented with acute non-neurological febrile illness without convulsion.

3. B-Exclusion criteria:

4. History of central nervous system (CNS) injuries including significant head trauma, CNS infection, afebrile seizure, receiving an iron supplementation or epileptogenic drug within the past month, history of perinatal complication or neuro-developmental delay or the presence of any chronic systemic diseases (metabolic, rheumatologic, malignancy, cardiac, and renal).

5. The exclusion criteria applied to case group were also applied to the control group.

All patients were assessed according to the following scheme of clinical evaluation and investigations:

1-Detailed medical history.

2-Complete general examination.

3-Complete Neurological examination.

Febrile convulsion (FC) has been defined as a convulsion associated with fever without acute disturbances in electrolyte balance or central nervous system infection in children with age ranging from 6 months to 5 years with no history of any afebrile seizures. Febrile convulsion is sub-classified as complex and simple. Complex FC is a seizure lasting more than 15 minutes and recurring within 24 hours [11].

\section{4-Electroencephalography (EEG) [done for cases].}

\section{5-Investigations (for both cases and controls):}

A-Laboratory investigations:

Complete blood count (CBC) including total and differential leukocytic count.

* Urine analysis and urine culture. 


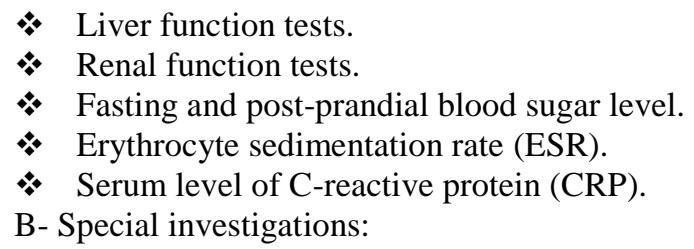

A venous blood sample was obtained from all the children in both groups and serum ferritin level, serum iron level, and total iron-binding capacity (TIBC) were measured for all children.

Anemia was defined as hemoglobin $(\mathrm{Hb})$ level of less than $110 \mathrm{~g} / \mathrm{L}$ in 6 months to 2 years and less than $11.5 \mathrm{~g} / \mathrm{dl}$ in 2 to 6 years. Iron deficiency was defined as serum ferritin level of less than $12 \mathrm{ng} / \mathrm{mL}$ if CRP was negative or $1+$, ferritin level of less than $30 \mathrm{ng} / \mathrm{mL}$ if CRP was $\geq 2+$, or serum iron levels of less than $22 \mu \mathrm{g} / \mathrm{dL}$ or transferrin saturation (a percentage calculated as serum iron concentration/TIBC x 100) of less than 16\% [12,13].

\section{Statistical analysis:-}

The data were collected, entered and analyzed using SPSS version 20 statistical software [14]. Data were expressed as mean \pm SD for quantitative variables, frequency and percentage for qualitative variables. Chi-square test $\left(\mathrm{x}^{2}\right)$ and t-test were used when appropriate. Differences were considered statistically significant at P-value of less than 0.05 $(\mathrm{P}<0.05)$.

\section{Results:-}

A total of 100 children, aged from 6-36 months were included in this cross-sectional case-control study according to the above mentioned criteria. Fifty children [27 males (54\%) and 23 females (46\%)] with ages ranged from 6 to 36 months (mean age \pm SD was $30.3 \pm 19.2$ months) who presented with febrile convulsion (case group) and 50 sex and age-matching children who presented with febrile illness without convulsion (control group) were included in this study as shown in table 1 which also shows that age, gender distribution, history of fever before admission and mean body temperature on admission were non-significant between the two groups, however history of previous seizures was significantly higher in cases (40\%) than in control group $(18 \%), \mathrm{P}=0.015$, also respiratory tract infection was significantly higher in case group $(60 \%)$ than in control group $(28 \%), \mathrm{P}=0.0012$, on the other hand, gastroenteritis showed no statistically significant difference between the two groups.

Table.2 shows the hematological and biochemical indices in the two groups. It shows that hemoglobin level $<110$ $\mathrm{g} / \mathrm{L}$, and microcytosis were significantly more frequent in febrile seizure group than in those with febrile illness without seizure [ $86 \%$ of febrile seizure cases had hemoglobin level $<110 \mathrm{~g} / \mathrm{L}$ vs. $68 \%$ of control ( $\mathrm{p}=0.032)$ ] and microcytosis was found in $86 \%$ of cases vs. $54 \%$ of control, $(\mathrm{p}=0.001)$ respectively), mean cell volume was [71.6(9.4) in cases vs. 76.6(12.1) in control group $(\mathrm{p}=0.02 .1)]$. Also median (IQR) serum iron ug/dl was significantly lower in cases [16.9 (14.4-23.8)] than in control group [20.7 (15.3-26.4)], $(\mathrm{P}=0.03)]$. Iron deficiency anemia was significantly more frequent in cases $(32.0 \%)$ than in children with febrile illness without convulsion (14\%), $(\mathrm{P}=0.032)$. Also, mean serum ferritin level $\mathrm{ng} / \mathrm{ml}$ was significantly lower in case group [38.52 \pm 11.38 ] than in control group [54.32 $13.46(\mathrm{P}=0.001)$, while mean serum transferrin level was found to be non significant between the two groups.

Table.3 shows number, type and duration of seizures among cases with and without iron deficiency. Generalized seizures were found significantly higher in febrile seizure cases with iron deficiency than in those without iron deficiency $(75 \%$ of cases with iron deficiency were having generalized seizure, vs. $41 \%$ of cases without iron deficiency, $(\mathrm{p}=0.025)$. On the other hand, focal seizures were significantly more frequent $(58.0 \%)$ in cases without iron deficiency than in cases with iron deficiency $(25 \%),(\mathrm{p}<0.025)$. Also, the mean duration of seizures was significantly longer in cases with iron deficiency (7.52 \pm 3.77$)$ minutes than in cases without iron deficiency $(5.17 \pm 2.95),(\mathrm{p}=0.01)$ 
Table 1:- Demographic data and clinical characteristics of cases and controls.

\begin{tabular}{|l|l|l|l|}
\hline $\begin{array}{l}\text { Demographic data } \\
\text { Groups }\end{array}$ & $\begin{array}{l}\text { Cases } \\
(\mathrm{N}=50)\end{array}$ & $\begin{array}{l}\text { Control } \\
(\mathrm{N}=50)\end{array}$ & P-value \\
\hline Age (Mean \pm SD) months & $30.3 \pm 19.2$ & $28.8 \pm 19.3$ & 0.77 \\
\hline Gender & & & 0.84 \\
\hline Male N(\%) & $27(54 \%)$ & $26(52 \%)$ & \\
\hline Female N(\%) & $23(46 \%)$ & $24(48 \%)$ & 0.436 \\
\hline Clinical characteristics & & & $0.015^{*}$ \\
\hline Fever before admission N(\%) & $45(90 \%)$ & 0.13 \\
\hline History of previous seizures N(\%) & $20(40 \%)$ & $9(18 \%)$ & $0.0012 *$ \\
\hline $\begin{array}{l}\text { Mean body temperature on admission } \\
\left(\text { Mean } \pm \text { SD) }{ }^{\circ} \mathrm{C}\right.\end{array}$ & $38.51 \pm 1.2$ & $38.0 \pm 1.2$ & $14(28 \%)$ \\
\hline Respiratory tract infection N(\%) & $30(60 \%)$ & $12(24 \%)$ & 0.317 \\
\hline Gastroenteritis N(\%) & $8(16 \%)$ & \\
\hline
\end{tabular}

* significant; SD: standard deviation; N: Number

Table 2:- Comparison of hematological and biochemical indices in cases and controls.

\begin{tabular}{|l|l|l|l|}
\hline I- Hematological indices & $\begin{array}{l}\text { Cases } \\
(\mathrm{N}=50)\end{array}$ & $\begin{array}{l}\text { Control } \\
(\mathrm{N}=50)\end{array}$ & $0.032^{*}$ \\
\hline Hemoglobin <110 g/L & $43(86 \%)$ & $34(68 \%)$ & 0.8 \\
\hline Packed cell volume <33\% & $39(78 \%)$ & $40(80 \%)$ & $0.02^{*}$ \\
\hline Mean cell volume (SD) & $71.6(9.4)$ & $76.6(12.1)$ & $<0.001^{*}$ \\
\hline Microcytosis (\%) & $43(86 \%)$ & $27(54 \%)$ & 0.6 \\
\hline Mean (SD) white blood cell count/ml & $13.0(7.4)$ & $14.1(8.3)$ & $0.03^{*}$ \\
\hline II- Biochemical indices & \multicolumn{3}{l}{} \\
\hline Median (IQR) serum iron level, ug/dl & $16.9(14.4-23.8)$ & $20.7(15.3-26.4)$ & $0.001^{* *}$ \\
\hline Mean serum ferritin( \pm SD), ng/ml & $38.52 \pm 11.38$ & $54.32 \pm 13.46$ & 0.83 \\
\hline Mean serum transferrin, mg/dl & $223(95)$ & $227(110)$ & $0.032^{*}$ \\
\hline Iron deficiency anemia & $16(32.0 \%)$ & $7(14.0 \%)$ & \\
\hline
\end{tabular}

** Highly significant; * significant. N: Number; g/L: gram per liter; SD: standard deviation; ug/dl: microgram per deciliter; ng/ml: nanogram per milliliter

Table 3:- The number, type and duration of seizures in febrile seizure cases with and without iron deficiency.

\begin{tabular}{|c|l|l|l|}
\hline Clinical & $\begin{array}{l}\text { Cases with iron } \\
\text { deficiency } \\
(\mathrm{N}=16)\end{array}$ & $\begin{array}{l}\text { Cases without iron } \\
\text { deficiency } \\
(\mathrm{N}=34)\end{array}$ & $1(1-2)$ \\
\hline Median (IQR) number of seizures & $1(1-2)$ & & 1.6 \\
\hline Seizure type N(\%) & & $20(58.0 \%)$ & $0.025^{*}$ \\
\hline -Focal & $4(25.0 \%)$ & $14(41 \%)$ & $0.01^{*}$ \\
\hline -Generalized & $12(75.0 \%)$ & $5.17 \pm 2.95$ & \\
\hline Mean duration of seizure in minutes $\pm(\mathrm{SD})$ & $7.52 \pm 3.77$ & & \\
\hline
\end{tabular}

** Highly significant, * significant; N: Number; SD standard deviation

\section{Discussion:-}

Febrile convulsions (FC) are considered the most important and common seizure type occurring in childhood between the age of six months and five years, it affects nearly $2-5 \%$ of neurologically healthy children. [5]

This case-control cross sectional study included 50 children presented with FC [27 males (54\%) and 23 females $(46 \%)$ ] and 50 age and sex matched control children [26 males (52\%) and 24 females (48\%)] who had febrile illness without seizure activity. The mean age \pm SD of cases was $30.3 \pm 19.2$ months and that of control group was $28.8 \pm 19.3$ months.

In the present study, the respiratory tract infection was significantly more frequent among cases than controls $(60 \%$ in cases vs. $28 \%$ in controls, $(\mathrm{p}=0.0012)$. On the other hand, gastroenteritis was present in $16 \%$ of cases and $24 \%$ of control but with no significant difference, In a case-control study done by Bidabadi and Mashouf [15] on 
association between iron deficiency anemia and febrile seizures, upper respiratory tract infection and gastroenteritis were reported among the most frequent underlying cause of fever in cases and controls.

In the current study, the iron status of both children with FC and that of age and sex matched control group was assessed and compared, also different hematological parameters for identification of iron deficiency anemia (IDA) were assessed [Hemoglobin $(\mathrm{Hb})$, hematocrite $(\mathrm{Ht})$, Mean cell volume (MCV), serum iron, and serum ferritin] and reported to be significantly lower in children with FC than in control group. The Hemoglobin level $<110 \mathrm{~g} / \mathrm{dl}$ was significantly more frequent in children with FC than in control [43(86\%) in cases with FC vs. 34(68\%) in control group, $\mathrm{P}=0.032],[\mathrm{MCV}( \pm \mathrm{SD})$ was $71.6( \pm 9.4)$ in cases vs. $76.6( \pm 12.1)$ in control, $\mathrm{p}=0.02]$, microcytosis was also significantly more frequent in children with FC than in those with febrile illness without seizure [43(86\%) in cases vs. $27(54 \%)$ in control $(\mathrm{p}=0.001)]$.

The median serum iron and mean serum ferritin levels were also found in this study to be significantly lower in FC children than in those with febrile illness without seizure activity [the median IQR of serum iron (ug/dl) was 16.9(14.4-23) in cases vs. 20.7(15.3-26.4) in control, $\mathrm{p}=0.03$, mean serum ferritin level (ng/ml) was $38.52 \pm 11.38$ in cases vs. 54.32 \pm 13.46 in control, $\mathrm{p}=0.001]$. Moreover, IDA was reported to be significantly more frequent in FC children than in control ( $32 \%$ of cases had IDA vs. only $14 \%$ of control $(\mathrm{p}=0.032)$.

Our results concerning decreased hematological and biochemical indices for IDA and increased frequency of IDA among children with FC were supported and in agreement with studies of Hartfield et al [6] and Modaresi et al, [16] who found that mean $\mathrm{Hb}, \mathrm{Ht}, \mathrm{MCV}$, serum iron and ferritin were significantly lower in FC children than in those with febrile illness without seizure. Also Akbayram et al [17] in their study reported a significantly lower serum iron level in children with FC than in healthy children group .

Another study [18] showed that the mean serum ferritin levels were found to be significantly lower in children with FC than in children with febrile illness without seizure. our results were also in accordance with a meta-analytic study done by Habibian et al [5] who found that IDA was 1.52 times more frequent among patients with FC than children with febrile illness without seizure, and added that IDA is considered a cofactor in producing FC in which genetics trigger the effect of IDA on the occurrence of FC.

Contrary to our findings, the study done by Bidabadi and Mashouf [15] showed that IDA was less frequent in children with FC in comparison to children with febrile illness without seizure .

In explanation for the causal relationship between IDA and FC, Schultz et al [19] showed that iron deficiency leads to dysfunction of myelination as well as disturbance of tyrosine and tryptophan hydroxylase synthesis which in turn plays an important role in production of neurotransmitters like (serotonin, dopamine and GABA) from the synaptic vesicles .

On analyzing the relationship between IDA and both the clinical type and duration of seizures in cases, we found that children with IDA were significantly having more generalized seizures than those without IDA (75\% of cases with IDA presented with generalized seizure vs. $41 \%$ of cases without IDA, $\mathrm{P}=0.025$ ). Regarding the duration of seizure among cases, it has been found that cases with IDA were having statistically significantly longer duration of seizures than those without IDA (mean $\pm \mathrm{SD}$ ) was $7.52 \pm 3.77$ minutes vs. $5.17 \pm 2.95$ respectively, $\mathrm{p}=0.01$ ). These results were in agreement with those of Fallah et al [1] who recorded that children with IDA were having longer duration of seizures.

\section{Conclusion:-}

Children with low serum iron level and those having iron deficiency anemia may be at higher risk for developing febrile convulsions when compared with those with febrile illness without seizure. This makes iron deficiency anemia as a possible modifiable nutritional risk factor for febrile convulsions among children.

\section{Recommendations:-}

Screening, early detection and correction of iron deficiency anemia should be considered in children presenting with febrile seizures, furthermore giving iron supplements should be routine in children who have a risk of developing febrile seizures like presence of family history of febrile convulsions. 


\section{Study limitation:-}

The study had some limitations, as small sample size, and also the serum ferritin level, being a non-specific acute phase reactant which may rise during any inflammatory condition.

\section{Financial support and sponsorship:-}

Nil.

\section{Conflicts of interest:-}

There are no conflicts of interest.

\section{References:-}

1. Fallah R, Tirandazi F, Ferdosian F, Fadavi N. Iron Deficiency And Iron Deficiency Anemia in Children With First Attack of Seizure and on Healthy Control Group : A Comparative Study. Iran J Child Neurol. 2014 Summer 8(3): 18-23.

2. Kliegman RM, Stanton BF, Geme III JWS, Schor NF. Nelson textbook of PEDIATRICS. 20th ed. Filladelphia: Elsevier Saunders; 2016.

3. Ghasemi F, Valizadeh F, Taee N. Iron-deficiency Anemia in Children with Febrile Seizure: A Case-Control Study. Iran J Child Neurol. 2014 Spring 8(2):38-44.

4. Yadav D and Chandra J. Iron deficiency: beyond anemia. Indian J Pediatr 2011;78(1):65-72.

5. Habibian N, Alipour A, Rezaianzadeh A. Association between Iron Deficiency Anemia and Febrile Convulsion in 3- to 60-Month-Old Children: A Systematic Review and Meta-Analysis. Iran J Med Sci. 2014;39(6):496-505.

6. Hartfield DS, Tan J, Yager JY, Rosychuk RJ, Spady D, Haines C, et al. The Association between Iron Deficiency and Febrile Seizures in Childhood. Clin Pediatr (Phila) 2009;48(4):420-6.

7. Momen A, Nikfar R, Karimi B. Evaluation of Iron Status in 9-month to 5-year-old Children with Febrile Seizures: 44 Iran J Child Neurol. 2014 Spring Vol 8 No 2: A Case-control Study in the South West of Iran. Iran J Child Neurol 2010;4(2):45-50

8. Talebian A, Momtazmanesh N. Febrile Seizures and Anemia. Iran J Child Neurol 2007; 2(1):31-3.

9. Salehi Omran MR, Tamaddoni A, Nasehi MM, Babazadeh H, Alizadeh Navaei R. Iron Status in Febrile Seizure: A Case-control Study. Iran J Child Neurol 2009:3(3):40-3.

10. Amirsalari S, Keihanidost Z, Ahmadi M, Sabouri A, Kavemanesh Z, Afshar P, et al. Relationship between Iron Deficiency Anemia and Febrile Seizures. Iran J Child Neurol 2010;14(1):27-30.

11. Mikati MA. Seizures in Childhood. In: Kliegman RM, Stanton BF, Schor NF, St. Geme JW, Behrman RE, editors. Nelson Textbook of Pediatrics. 19th edition. Philadelphia: Saunders; 2011. pp. 2013-7. 12- Carvalho AG, Lira PI, Barros Mde F, Aléssio ML, Lima Mde C, Carbonneau MA, Berger J, Léger CL. Diagnosis of iron deficiency anemia in children of Northeast Brazil. Rev Saude Publica. 2010;44(3):513-9. 13- Kumari PL, Nair MK, Nair SM, Kailas L, Geetha S. Iron deficiency as a risk factor for simple febrile seizures - a case control study. Indian Pediatr. 2012;49(1):17-9.

12. Levesque R (editor): SPSS Programming and Data Management: A Guide for SPSS and SAS Users, 4th Edition, SPSS Inc., Chicago Ill. 2007.

13. Bidabadi E, Mashouf M. Association between iron deficiency anemia and first febrile convulsion: A casecontrol study. Seizure 2009; 18(5):347-51.

14. Modaresi M, Mahmoudian T, Yaghini O, Kelishadi R, Golestani H, Tavasoli A, et al. Is Iron Insufficiency Associated With Febrile Seizure? Experience in an Iranian Hospital. J Compr Ped 2012; 3(1):21-4.

15. Akbayram S, Cemek M, Büyükben A, Aymelek F, Karaman S, Yilmaz F, et al. Major and minor bio-element status in children with febrile seizure. Bratisl Lek Listy. 2012;113:421-3.

16. Vaswani RK, Dharaskar PG, Kulkarni S, Ghosh K. Iron deficiency as a risk factor for first febrile seizure. Indian Pediatr. 2010;47:437-9.

17. Schultz K, Kroner A, David S. Iron efflux from astrocytes plays a role in the remyelination. J Neuroscience 2012; 32: 4841-7. 